\title{
$\mathrm{DFIG}$ 풍력터빈이 연계된 전력계통의 $\mathrm{CCT}$ 영향분석
}

\author{
서규석 ${ }^{1^{*}}$, 박지호 ${ }^{1}$ \\ ${ }^{1}$ 거제대학교 선박전기과

\section{CCT Analysis of Power System Connected to DFIG Wind Turbine}

\author{
Gyu-Seok Seo ${ }^{1^{*}}$ and Ji-Ho Park ${ }^{1}$ \\ ${ }^{1}$ Dept. of Electrical Engineering, Koje College
}

\begin{abstract}
요 약 풍력발전시스템은 기존의 발전시스템과 매우 다르다. 그러므로 전력계통에 풍력시스템을 연계하기 위해서는 동적특성에 대한 연구가 필요하다. 풍력발전기의 안정도해석은 전력계통의 운영에 있어서 중요 쟁점이다. 기존의 동 기발전기만으로 구성된 전력계통의 위상각 안정도는 풍력발전기가 포함되면 그 결과가 달라진다. 즉, 풍력터빈에 연 계된 발전기는 대부분 비동기인 유도발전기이기 때문이다. 위상각의 동기화 여부로 판별하는 위상각 안정도는 임계고 장제거시간(CCT)을 계산하여 평가한다. 계통해석용 풍력터빈의 모델은 다양하여 그 해석에 어려움이 있으나 지금은 크게 4가지 타입으로 표준화가 되어있다. 본 논문에서는 PSS/E-32에서 제공하는 풍력터빈의 3 번째 표준모델인 DFIG(Doubly-Fed induction Generator)모델을 이용하여 풍력단지가 연계된 전력계통의 CCT를 풍력단지의 위치와 용량 을 고려하여 분석한다.
\end{abstract}

\begin{abstract}
Wind generation systems are very different in nature from conventional generation systems. Therefore it is necessary to research dynamic characteristics of wind generation systems connected to a power system. The stability analysis of wind turbine generator is an important issue in the operation of the power system. The result of angular stability of the power system that consists of only synchronous generators is different from that of the power system including wind turbine generators. This is due to the fact that generators connected to wind turbines are generally induction generators. The angular stability assessing synchronization of generators is determined by its corresponding critical clearing time(CCT). Wind turbine models for the analysis of power system are varied and difficult to use, but now these are standardized into four types. In this paper, the analysis of the CCT of the power system connected to wind farm considering the location and capacity is performed by using DFIG(Doubly-Fed induction Generator) wind turbine built-in type3 model in PSS/E-32.
\end{abstract}

Key Words : Wind Generation Systems, Angular Stability, Critical Clearing Time, DFIG

\section{1. 서론}

신재생 에너지를 이용하여 전기를 생산할 수 있는 방 법들 중 하나가 바람에 포함된 에너지를 전기로 변환하 는 것이다. 풍력은 거의 무한한 에너지원이고 풍력을 이 용한 발전이 환경에 미치는 악영향은 매우 미미하다고 할 수 있다. 하지만 풍력발전 시스템은 기존의 동기발전
기만으로 구성된 전력계통과는 본질적으로 많은 차이를 가지고 있다. 따라서 풍력발전 시스템이 기존의 전력계통 과 연계될 때는 기존의 동기발전기들과의 상호작용이 어 떻게 일어나는지 알아야만 한다[1]. 특히 전력계통의 사 고 발생 시 안정도 해석은 필수적이다. 전력계통은 매우 복잡한 시스템이므로 사고에 영향을 받기 쉽다. 단락사고 는 전력계통에 매우 일반적인 사고이다. 이러한 사고는

\footnotetext{
이 논문은 2012년도 정부(교육과학기술부)의 재원으로 한국연구재단의 지원을 받아 수행된 기초연구사업임 (No.2012R1A1A1042577)

"Corresponding Author : Gyu-Seok Seo(Koje College)

Tel: +82-55-680-1558 email: gsseo@koje.ac.kr
} 
사고 인근의 발전기의 회전자를 가속시키고 전력계통의 전력의 흐름도 동요시킨다[2]. 사고를 제거함으로써 발전 기가 감속된다면 동기화를 유지할 수 있다. 하지만 감속 되지 않으면 시스템은 불안정하게 된다. 임계고장제거시 간(CCT: Critical Clearing Time)[3]은 발전기의 안정도를 유지하기 위한 최대의 고장제거 시간이다. 풍력발전기를 전력계통에 연계하여 특성을 해석하기 위해서는 해석용 모델이 필요한데 이러한 필요에 따라 풍력모델의 4 가지 표준모델이 정립되었다. 본 논문에서는 4 가지 표준모델 중에서 현재 많이 설치되어 운영되고 있는 DFIG를 21모 선의 예제시스템에 연계시켜 풍력발전기의 전력계통에 대한 영향력을 임계고장제거시간 비교를 통해 분석한다. 논문의 초점은 예제 시스템에 풍력단지의 연계위치와 풍 력단지의 용량에 따른 임계고장제거시간 변화에 둔다. 사 용된 시뮬레이션 툴은 $\mathrm{PSS} / \mathrm{E}$ 버전32이다. $\mathrm{PSSE} / \mathrm{E}$ 에서 $\mathrm{DFIG}$ 은 타입 3 으로 표준화되어 구현되어 있다. 이것을 이 용하여 임계고장제거시간을 계산하고 이 모델의 장점과 단점도 비교한다.

\section{2. 본론}

\section{1 풍력터빈 모델}

풍력에너지는 풍력터빈을 통해 기계적 에너지로 변환 되고 발전기로 전달되어 전기에너지로 변환된다. 풍력터 빈은 매우 다양한 종류가 존재하고 각각의 장단점이 있 으며, 크게 고정속도 풍력터빈과 가변속도 풍력터빈으로 분류해 볼 수 있다. Fig. 1에 나타낸 고정속도 풍력터빈은 그리드에 직접 연결된 농형유도발전기를 사용한다.

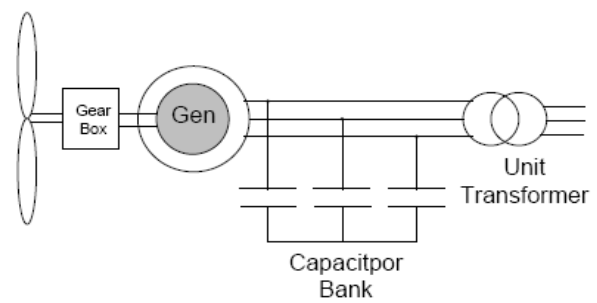

[Fig. 1] Fixed speed wind turbine

고정속도 풍력터빈은 구조가 간단하고 가격이 싸지만 회전자의 속도가 고정되어 있으므로 높은 풍속에도 견디 는 힘을 가지기 위해서 기계적으로 강인해야만 한다. 또 한 효율이 낮고 무효전력을 소비만 하므로 별도의 무효 전력 보상장치를 필요로 한다. 따라서 전압제어가 불가능
하여 전압안정도 뿐 아니라 사고가 발생하면 전력계통의 과도안정도에도 나쁜 영향을 미치므로 지금은 거의 사용 하지 않고 있다.

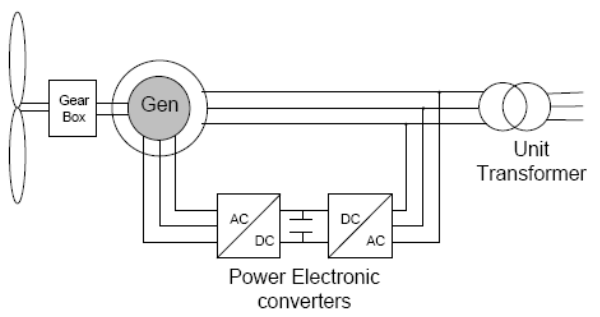

[Fig. 2] Variable-speed wind turbine

Fig. 2는 가변속도 풍력발전기를 나타낸 것이다. 이 발 전기는 전력전자 컨버터와 $\mathrm{DFIG}$ 를 사용한다. 컨버터는 회전자와 연결되고 고정자는 그리드와 직접 연결된다. 넓 은 범위의 풍속에 대해 높은 출력을 발생시킬 수 있도록 제어가 가능하다. 풍속이 정격 이상으로 높을 때는 회전 자 블레이드의 피치각을 제어하여 전력을 제어한다. 총 전력의 $20 \sim 30 \%$ 만이 컨버터를 통하므로 고출력의 풍력 터빈으로 적합하다. 따라서 컨버터의 크기를 줄일 수 있 고 가격과 손실을 줄일 수 있다.

\section{2 테스트 시스템}

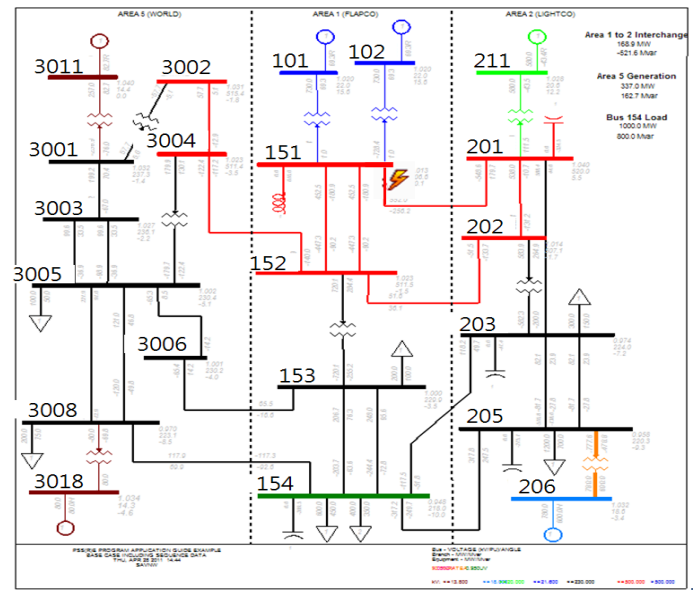

[Fig. 3] Test system

시뮬레이션에 사용된 시스템은 총 발전량이 $3,260 \mathrm{MW}$ 이고 모선이 21 개, 선로는 23 개 총부하가 $320 \mathrm{MW}$ 인 시스 템이다[1]. 발전기 안정도를 모의하기 위해 시스템의 151 번 모선 근처에서 3 상 지락사고를 가정한다. 


\section{3 시뮬레이션 및 결과}

본 논문에서는 아래의 세 가지 경우에 대한 시뮬레이 션을 수행하여 임계고장제거시간을 계산하고 비교한다.

(1) 시스템의 발전기가 모두 동기발전기인 경우

(2) 특정 모선에 풍력단지를 연계한 경우

(3) 연계된 풍력단지의 출력을 조정할 경우

\subsection{1 풍력단지가 연계되지 않은 경우의 모의결과}

151 번 모선 근처에 3 상 지락사고를 가정하고 151번 모선과 201번 모선 사이의 선로를 차단하여 사고를 제거 하는 것을 모의한다.
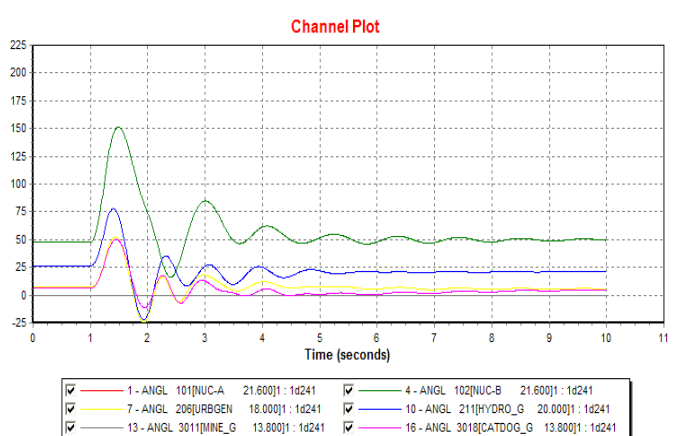

[Fig. 4] Angle response at clearing time $241 \mathrm{~ms}$

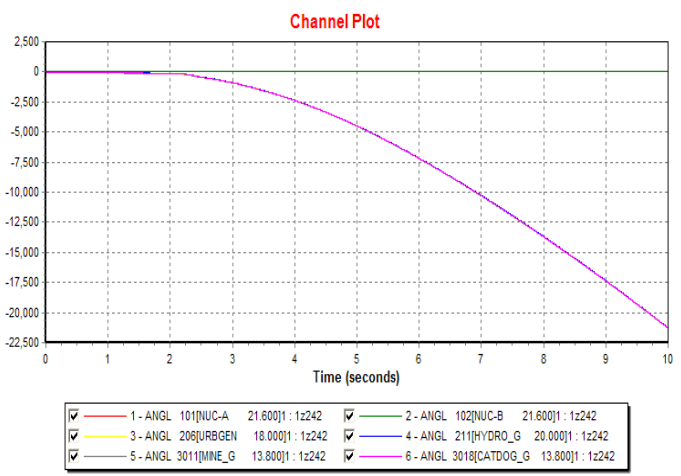

[Fig. 5] Angle response at clearing time $242 \mathrm{~ms}$

발전기가 모두 동기발전기인 경우를 기본 케이스로 설 정하고 모의하여 계산된 CCT는 $241 \mathrm{~ms}$ 이다. Fig. 4 는 임 계시간에서의 응답이고 Fig. 5 는 $242 \mathrm{~ms}$ 에서의 응답이다.

\subsection{2 풍력단지가 연계된 경우의 모의결과}

용량이 100MW인 풍력단지를 151번 모선, 201번 모 선, 202번 모선, 152번 모선, 205번 모선 그리고 3008번
모선에 연결하여 각각 $\mathrm{CCT}$ 를 구하였다. 사용된 풍력발 전기는 $\mathrm{PSS} / \mathrm{E}-32$ 의 사용자 정의 모델 $\mathrm{GE} 1.5 \mathrm{MW}$ 이고, 이 발전기 67대를 연결하여 풍력단지를 구성했다. 151번 모 선에 연계된 경우, Fig. 6과 Fig. 7에 나타낸 것처럼 $\mathrm{CCT}$ 는 $250 \mathrm{~ms}$ 이다.

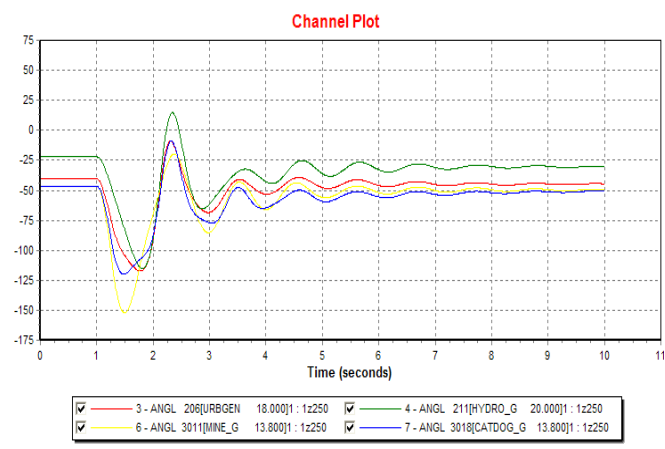

[Fig. 6] Angle response at clearing time 250ms(Bus151)

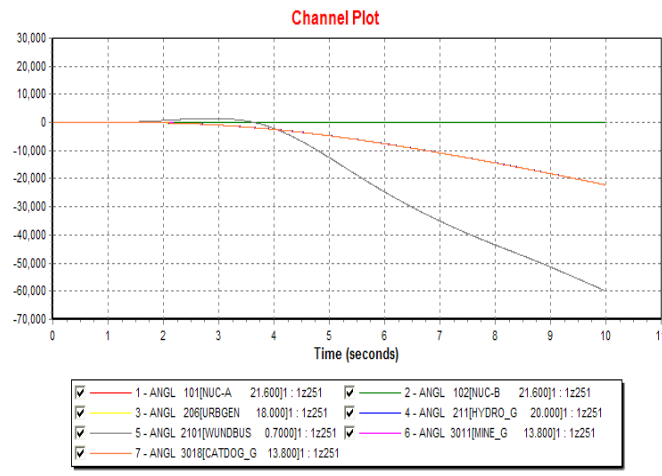

[Fig. 7] Angle response at clearing time 251ms(Bus151)

201번 모선, 202번 모선 그리고 152번 모선의 경우, Fig. 8과 Fig. 9에 보인 것처럼 기본 케이스보다 더 작은 값의 $\mathrm{CCT}=225 \mathrm{~ms}$ 를 가진다.

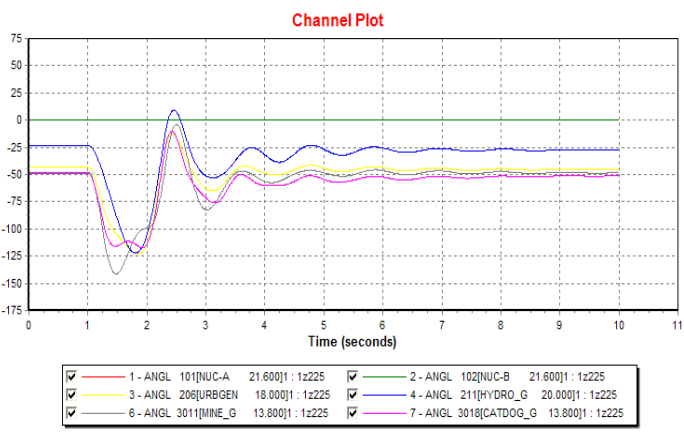

[Fig. 8] Angle response at clearing time 225ms(Bus201) 


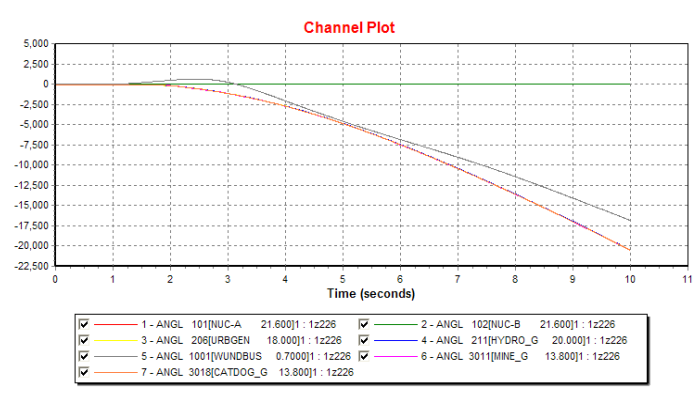

[Fig. 9] Angle response at clearing time 226ms(Bus201)

3008 번 모선과 205 번 모선의 경우, 가장 작은 $\mathrm{CCT}=$ $216 \mathrm{~ms}$ 를 나타내었다.

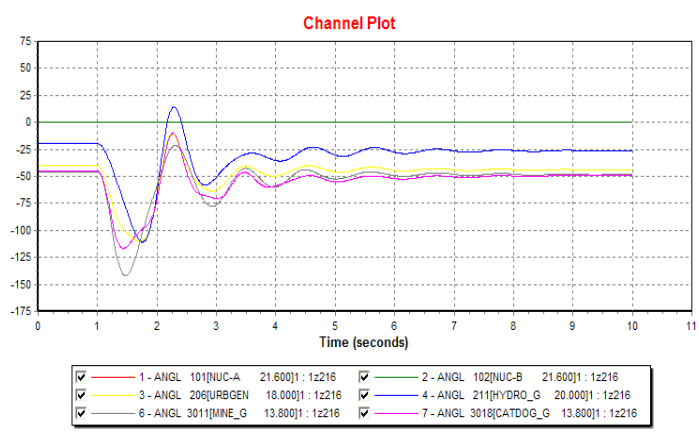

[Fig. 10] Angle response at clearing time 216ms(Bus205)

시뮬레이션 결과 풍력단지가 연결된 위치에 따라 CCT 가 서로 다르게 나왔다. DFIG는 무효전력을 제어하는 능 력을 가지므로 안정도를 향상시킬 수 있어 기본 케이스 보다 CCT가 높아질 수도 있으나 연계된 위치에 따라 $\mathrm{CCT}$ 가 더 나쁘게 나타나는 경우도 있다.

\subsection{3 풍력발전량이 변하는 경우의 모의결과}

151 번 모선에 연결된 풍력단지의 용량을 점차적으로 증가시켜서 $\mathrm{CCT}$ 를 계산한 결과 $100 \mathrm{MW}$ 일 때는 $\mathrm{CCT}$ 가 $250 \mathrm{~ms}, 200 \mathrm{MW}$ 일 때는 CCT가 $266 \mathrm{~ms}$ 그리고 $300 \mathrm{MW}$ 일 때는 $275 \mathrm{~ms}$ 로 증가하는 추세를 보였다. 하지만 용량을 더욱 증가시켰을 때는 $\mathrm{CCT}$ 가 계속적으로 감소했다. 본 논문에서 사용한 풍력발전기 모델은 PSSE-32의 내장모 델인 type $3 \mathrm{GE} 1.5 \mathrm{MW}$ 의 풍력터빈 모델이다. 이 모델은 Fault Ride Through (FRT) 기능이 없다. 또한 회전자의 전류에 표현이 없다. 실제의 풍력발전기는 컨버터의 전류 에 제한이 있으므로 사고시에 전류제한이 생긴다. 이 모 델은 이러한 제한을 반영하지 못하므로 계산된 CCT가 실제의 $\mathrm{CCT}$ 보다 매우 낙관적일 수 있는 단점을 가진다.
또한 이 모델은 풍속의 변화를 반영할 수 없는 일정풍속 에서 동작하므로 풍속의 영향을 모의할 수 없다.

\section{3. 결론}

본 논문은 임계고장제거시간의 계산에 의한 위상각 안 정도에 초점을 두었다. 전력계통에서 $\mathrm{CCT}$ 의 값은 안정 도를 평가하는 지표의 역할을 한다. 따라서 풍력발전기가 연계된 전력계통에 대하여 반드시 CCT를 계산할 필요가 있다. 이 때 고려한 사항은 테스트 시스템에 3상 사고를 가정하고 비교를 위하여 동기발전기만 있는 경우, 동기발 전기 1 대를 풍력발전기로 대체한 경우 그리고 풍력발전 기의 출력 변화시키는 경우이다. 모의의 결과에서 동기발 전기 1대를 풍력발전기로 대체한 경우 발전기가 모두 동 기발전기인 경우에 비하여 CCT가 증가할 수도 있고 감 소할 수도 있다. 즉 풍력발전기가 연계된 위치에 따라 $\mathrm{CCT}$ 는 달라진다. 그 이유는 풍력발전기의 연계 위치에 따라 근접한 동기발전기에 직접적인 영향을 주기 때문이 다. 또한 풍력발전기의 출력의 증가는 일반적으로 안정도 에 나쁜 영향을 준다는 것을 알 수 있다. 하지만 이러한 영향들은 일반화할 수는 없다. 그 이유는 풍력발전기가 연계된 위치가 가장 큰 변수이기 때문이다.

본 논문에서 사용된 $\mathrm{PSS} / \mathrm{E}$ 에 내장된 모델인 type3 모 델은 사용자가 전력-속도 곡선을 정의할 수 있어 전력계 통 해석에 유연성을 제공한다. 시뮬레이션에 사용된 type3 풍력발전기는 FRT모델이 포함되어 있지 않는 단점 때문에 실제보다 더 낙관적인 $\mathrm{CCT}$ 를 계산할 수도 있다. 또한 풍속이 항상 일정하다고 가정하기 때문에 풍속변화 에 따른 터빈의 응답을 모의할 수 없다. 하지만 본 논문 에서 수행한 모의 결과에서 전력계통의 안정도에 영향을 미치는 결정적인 요인은 풍력발전기가 연계된 위치에 따 라 발전기의 다수를 차지하는 동기발전기의 응답이 달라 진다는 것이다.

\section{References}

[1] Clemens Jauch, Poul Sorensen, Ian Norheim, Carsten Rasmussen "Simulation of the Impact of Wind Power on the Transient Fault Behavior of the Nordic Power System", Electric Power System Research 77 (2007) 135-144

DOI: http://dx.doi.org/10.1016/j.epsr.2006.02.006

[2] Sun T., Chen Z., Blaabjerg F. "Voltage Recovery of 
Grid-connected Wind Turbines after a Short-circuit Fault", Annual Conference of the IEEE Industrial Electronics Society, Virginia, USA, 2003

DOI: http://dx.doi.org/10.1109/IECON.2003.1280678

[3] Salman S. K., Teo A. L. I. "Investigation in to the Estimation of the Critical Clearing Time of a Grid Connected Wind Power Based Embedded Generator", Proceedings of the IEEE/PES transmission and distribution Conference and exhibition 2002, Asis Pacific Pucific, Vol. 11 2002, p975-980

DOI: http://dx.doi.org/10.1109/TDC.2002.1177609

[4] "PSS/E-32 Program Application Guide Vol. 1", Shaw Power Technologies Inc.

서 규 석(Gyu-Seok Seo)

[정회원]

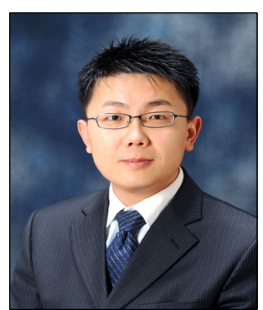

- 2003년 2월 : 경북대학교 전기공 학과 (공학사)

- 2005년 2월 : 경북대학교 대학원 전기공학과 (공학석사)

- 2009년 2월 : 경북대학교 대학원 전기공학과 (공학박사)

- 2009년 2월 현재 : 거제대학교 선박전기과 교수

<관심분야>

배전시스템 운영 및 제어, 스마트 그리드

\section{박 지 호(Ji-Ho Park)}

[정회원]

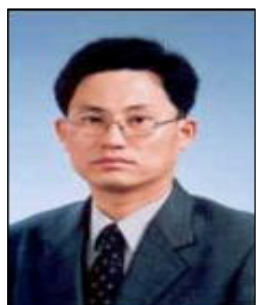

- 1991년 2월 : 경북대학교 전기공 학과 (공학사)

- 1996년 8월 : 경북대학교 대학원 전기공학과 (공학석사)

- 2001년 2월 : 경북대학교 대학원 전기공학과 (공학박사)

- 2013년 3월 현재 : 거제대학교 선박전기과 초빙교원

<관심분야>

전력계통 안정도, 스마트 그리드 